\title{
Un análisis de la primera ley sobre anticoncepción en Argentina. El Programa de Procreación Responsable en la provincia de La Pampa
}

\author{
María Herminia Di Liscia (*) \\ (*) Instituto Interdisciplinario de Estudios de la Mujer, Facultad de Ciencias Humanas, \\ Universidad Nacional de La Pampa, Argentina. \\ mhdiliscia@cpenet.com.ar
}

Dynamis

[0211-9536] 2012; 32 (1): 209-230

Fecha de recepción: 8 de julio de 2010

Fecha de aceptación: 28 de noviembre de 2011

SUMARIO: 1.- Introducción. 2.-La recuperación democrática y las demandas de las mujeres. 3.-La cuestión de la mujer en La Pampa. Contexto de surgimiento de la Ley de Procreación Responsable. 4.-Contenido y debate de la Ley de Procreación Responsable. 5.-Del debate a la promulgación. 6.-La procreación responsable y la matriz del peronismo: un significado posible. 7.-Conclusiones y proyecciones al presente.

RESUMEN: La sanción de una ley requiere procesos previos de negociación con el objeto de considerar antecedentes, argumentos, apoyos y terminología apropiada para su abordaje. EI campo jurídico es un campo discursivo en el que se desarrolla una doble lucha: por la nominación y por colocar en el uso cotidiano lo que esa ley establece. Se desatan así procesos conflictivos en los que agentes sociales se enfrentan con partidos políticos, con instituciones y con sus propias identidades políticas y subjetivas. El presente trabajo analiza la gestación de la Ley 1363, aprobada en noviembre de 1991 en la Legislatura de la provincia de La Pampa (Argentina), a través de la cual se creó el Programa Provincial de Procreación Responsable, primera norma provincial del país sobre anticoncepción. Se toman en consideración los discursos que aluden especialmente a las mujeres puesto que, si bien la reproducción también involucra a los varones, la cultura superpone la maternidad a la identidad femenina, lo que hace que las referencias tengan un peso diferencial sobre la condición de las mujeres. Presentamos la singularidad del caso y su potencial analítico para comprender otros, utilizando como material empírico el debate parlamentario, entrevistas a la autora de la ley y a informantes clave. Intentamos responder a preguntas como: ¿cuál es el contexto nacional y provincial en el que se enmarca la Ley de Procreación Responsable?, y ¿cuáles fueron las estrategias utilizadas para llegar a ella? Dentro de la cosmovisión del peronismo sobre la mujer, ¿cómo se articula la anticoncepción?, y ¿qué significados se pusieron en juego en la expresión «procreación responsable»? Finalmente, se presenta un somero balance sobre la aplicación de la ley.

PALABRAS CLAVE: Procreación responsable, anticoncepción, género, peronismo, derechos.

KEY WORDS: Responsible procreation, contraception, gender, Peronism, rights. 


\section{Introducción $(*)$}

Para llegar a la sanción de una ley, se requiere de procesos previos dirigidos a aquilatar apoyos, argumentos, antecedentes; la búsqueda de términos que les den existencia y estrategias de abordaje. El campo jurídico es un campo discursivo en el que se desarrolla una lucha doble: por la nominación y por colocar en el uso cotidiano lo que esa ley establece ${ }^{1}$. Se desatan así procesos conflictivos en los que agentes sociales se enfrentan con partidos políticos, con instituciones y con sus propias identidades políticas y subjetivas. En el análisis de una norma, no podemos dejar de señalar la performatividad del lenguaje, que permite advertir que las palabras exceden su capacidad de representar - en el presente y en el futuro- una entidad, un colectivo, un interés; modelan y prescriben las siluetas de las identidades dentro de un lugar y un orden social.

En este artículo, presentamos un análisis acerca de la Ley 1363, aprobada en noviembre de 1991 en la Legislatura de la provincia de La Pampa (Argentina), a través de la que se crea el Programa Provincial de Procreación Responsable, la primera norma provincial del país sobre anticoncepción. Se toman en consideración los discursos que aluden especialmente a las mujeres puesto que, si bien la reproducción también involucra a los varones, la cultura superpone la maternidad a la identidad femenina, lo que hace que las referencias tengan un peso diferencial sobre la condición de las mujeres. Por lo tanto, la discusión de esta norma remite a la subversión de significados ancestrales que impugnan una inscripción de lo materno esencializada y naturalizada por creencias y doctrinas, además de por el imaginario social ${ }^{2}$.

$\left({ }^{*}\right) \quad$ Una primera versión de este trabajo fue presentada en el Seminario internacional: «Anticoncepción, maternidades y derechos de la salud en los siglos XX y XXI», realizado en Buenos Aires (Argentina) el 10 y 11 de junio de 2010, organizado por el Instituto Interdisciplinario de Estudios de Género, UBA y el Programa Master Erasmus Mundus Gemma del Instituto de Estudios de la Mujer de la Universidad de Granada.

1. Segato, Rita. El derecho a nombrar el sufrimiento en el Derecho. Documento de la Asamblea Permanente por los Derechos Humanos, Argentina. Jornadas Regionales para Funcionarios de Derechos Humanos, Ushuaia, abril de 2010 [documento inédito].

2. Debemos recordar que en los inicio de los 90 no se había difundido ni generalizado el uso del condón como preventivo del HIV/SIDA, lo que redunda en la utilización casi exclusiva de métodos que apliquen las mujeres y su reflejo en la regulación de sus capacidades maternales. 
En el recorrido a realizar, aludimos a la constitución de la ciudadanía y a los dominios de los derechos, entendidos en la doble perspectiva de su establecimiento formal en normas y legislaciones, y de las demandas de las mujeres a través de la identificación de lo que Graciela Di Marco denomina «discurso de derechos», es decir, el conjunto de prácticas y lenguajes que desnaturalizan la subordinación ${ }^{3}$. Como han señalado varias autoras ${ }^{4}$, los derechos sexuales y reproductivos ponen en jaque las categorías clásicas de la ciudadanía y el ejercicio de la igualdad y permiten advertir que estos derechos «son la base misma de la posibilidad de participación efectiva de las mujeres tanto en la sociedad civil como en la vida política (...) y, por lo tanto, asegurar una condición crucial para que las mujeres lleguen a ser miembros libres e iguales de la sociedad $»^{5}$.

Los derechos reproductivos hacen referencia a las decisiones y libertades que una persona debe gozar para poder decidir sobre sus capacidades reproductivas: la cantidad y espaciamiento de los hijos, el acceso a asesoramiento y provisión de anticonceptivos apropiados, a servicios adecuados ante situaciones de infertilidad y el derecho al aborto seguro, legal y accesible. Los derechos sexuales suponen la libertad para elegir y ejercer plenamente la sexualidad sin peligro de abuso, coerción, violencia o discriminación.

Desde una perspectiva de defensa de la autonomía de las mujeres, el análisis de contenidos igualitarios ciudadanos nos lleva a sostener, en coincidencia con Jacques Rancière que las prácticas y discursos de instituciones, de partidos políticos, en definitiva, de la política - en términos convencionales - se basan en una mera suposición de que todos somos iguales ${ }^{6}$. La consideración de esta afirmación como una mera suposición procede de la acción y de la palabra incorrecta de aquellos y aquellas que el orden social y político no ha autorizado a expresarse. Esta enunciación expone un litigio y argumentos que alborotan y desquician los espacios

\footnotetext{
3. Di Marco, Graciela. El impacto de la participación en los cambios de los modelos de género. In: Schmuckler, Beatriz; Di Marco, Graciela. Madres y democratización de la familia en la Argentina contemporánea. Buenos Aires: Biblos; 1997, p. 47-63.

4. Fraser, Nancy. La lucha por las necesidades: Esbozo de una teoría crítica socialista-feminista de la cultura política del capitalismo tardío. Debate Feminista. 1991; 4: 18-39; Mouffe, Chantal. Feminismo, ciudadanía y política democrática radical. Debate Feminista. 1993; 7: 3-22; Pateman, Carole. Feminismo y democracia. Debate Feminista. 1990; 1: 7-28.

5. Held, David. Ciudadanía y autonomía. Ágora. Cuaderno de Estudios Políticos. 1997; 7: 43-71 (59).

6. Rancière, Jacques. El desacuerdo. Política y filosofía. Buenos Aires: Nueva Visión; 2007.
} 
y las funciones prescritas por la sociedad. La verdadera política permite, entonces, la irrupción de otras partes de la comunidad, es decir, la parte de las que no tienen parte. Se instala, en términos de Jacques Rancière, un desacuerdo que no es exclusivamente lingüístico, sino referido a la situación misma de quienes hablan, en su existencia ${ }^{7}$.

Pretendemos registrar y analizar un proceso en el que, al menos en la consideración legal, se sanciona una norma que va a plantear un derecho que nunca tuvo existencia dentro del lenguaje jurídico: decidir sobre las pautas reproductivas.

Además del debate en la Legislatura de la provincia de La Pampa ${ }^{8}$, la información empírica primaria que utilizamos surge de entrevistas a la autora de la ley, Silvia Gallego ${ }^{9}$, complementada por otras a informantes clave $^{10}$, partícipes del proceso estudiado. Varios motivos fundamentan esta elección metodológica: por una parte, porque es la única manera de reconstruir un proceso que, con otras fuentes, no es posible de conocer, y es la trastienda de la gestación de una norma; por otra, porque nos interesa recobrar las experiencias de sus protagonistas ${ }^{11}$, mujeres que no

7. «Por desacuerdo se entenderá un tipo determinado de situación de habla: aquella en la que uno de los interlocutores entiende y a la vez no entiende lo que dice el otro. El desacuerdo no es el conflicto entre quien dice blanco y quien dice negro. Es el existente entre quien dice blanco y quien dice blanco pero no entiende lo mismo o no entiende que el otro dice lo mismo con el nombre de la blancura». Rancière, n. 6, p. 8.

8. Diario de Sesiones de la Honorable Cámara de Diputados. Provincia de La Pampa, 27 de noviembre de 1991, p. 835-846. Debe señalarse además que el poder legislativo de la provincia de la Pampa es unicameral.

9. Nació en General Pico (La Pampa) en 1948. Hija de María del Carmen Balent de Gallego, una de las primeras legisladoras de la provincia Eva Perón (nombre que originalmente tuvo La Pampa). Realizó estudios secundarios completos. Se casó en 1969, tuvo un hijo y una hija. Fue empleada de la Legislatura, secretaria privada del vicegobernador hasta el golpe de 1976. Enviudó en 1994. A partir de la recuperación democrática fue secretaria privada del gobernador, diputada provincial en dos períodos, ministra de bienestar social y senadora nacional. Desde enero de 2010 integra el Directorio del Banco de la Nación Argentina. Mantuvimos durante 2009, dos entrevistas abiertas a fin de construir su historia de vida focalizada en su trayectoria política.

10. Edith Vivona (psicóloga, directora de Salud Mental 1984-1993), Nilda Erbetta (médica a cargo de Sanidad Escolar en el período 1984-1993) y Gloria Luoni (trabajadora Social, asesora de Silvia Gallego durante su primer mandato de diputada). Realizamos en 2010 entrevistas breves cuya consigna fue relatar el contexto — en el marco del trabajo de cada una de ellas - de la redacción y tratamiento de la Ley de Procreación Responsable.

11. Tomamos el concepto de experiencia desde una perspectiva feminista, a fin de dar cuenta de las respuestas mentales y emocionales en las que se yuxtaponen elementos de subordinación y resistencia al orden patriarcal y la creación de nuevos modos de ser. Martínez, 
tuvieron referencias de apoyo en su entorno político y que desempeñaron papeles intransferibles por la posición ocupada. Así, presentamos la singularidad del caso y su potencial analítico para comprender otros, a la vez que pudimos advertir el recorrido de itinerarios similares en narraciones de otras legisladoras ${ }^{12}$. Buscamos responder a preguntas como: ¿cuál es el contexto nacional y provincial en el que se enmarca la Ley de Procreación Responsable?, y ¿cuáles fueron las estrategias utilizadas para llegar a ella? Dentro de la cosmovisión del peronismo sobre la mujer, ¿cómo se articula la anticoncepción?, y ¿qué significados se pusieron en juego en la expresión «procreación responsable»? Finalmente, presentamos un somero balance sobre la aplicación de la ley.

\section{La recuperación democrática y las demandas de las mujeres}

A partir de la recuperación democrática, se abrió una coyuntura política favorable a la incorporación de demandas de las mujeres. Los avances del feminismo en los organismos internacionales, más la presión del movimiento de mujeres, posibilitaron la inclusión en la agenda política de cuestiones vinculadas tanto al ámbito público (representación política, autoridad en la familia, problemas en la esfera laboral) como al ejercicio de los derechos sobre el cuerpo: procreación, sexualidad, violencia, prostitución, acoso y violación; como así también el ingreso de algunas mujeres dentro del aparato estatal.

Alicia. La identidad femenina. Crisis y construcción. In: Tarrés, María Luisa, comp. La voluntad de ser. Mujeres en los noventa. México: El Colegio de México; 1992, p. 65-84.

12. Si bien son posteriores, nos referimos a las intervenciones de las senadoras Isidori (provincia de Río Negro) y Giri (Córdoba) en el debate en la Cámara de Senadores de la Ley de implementación de métodos de anticoncepción quirúrgica, lo que muestra la repetición de los mismos escollos y argumentos que deben sortearse para aprobar leyes referidas a derechos sexuales y reproductivos. Al respecto, consultar: República Argentina. Versión taquigráfica. Cámara de Senadores de la Nación. Dirección de Información Parlamentaria, 9 de agosto de 2006. El recurso de enriquecer el debate parlamentario con información de entrevistas para un análisis de caso también es utilizado por Brown, Josefina. De cuando lo privado se hace público o de cómo se construyen las políticas sobre sexualidad y (no) reproducción. El caso de Mendoza. In: Petracci, Mónica; Ramos, Silvina, comps. La política pública de salud y derechos sexuales y reproductivos en la Argentina: aportes para comprender su historia. Buenos Aires: CEDES; 2006, p. 131-155. 
Las leyes de patria potestad compartida (n. 23234 de 1985) y de divorcio (n. ${ }^{\circ} 23515$ de 1987), las primeras que modificaron la situación de las mujeres en el gobierno de Raúl Alfonsín (1983-1989), tuvieron por autoras a diputadas, que generalmente no gozaron del apoyo de sus partidos políticos, sino sobre todo de las organizaciones de mujeres. A mediados de 1986, se derogaron una serie de decretos restrictivos que, desde los años setenta, regulaban el uso de anticonceptivos y obstaculizaban el acceso a la información sobre el tema ${ }^{13}$. Por primera vez se reconoció en el plano jurídico a través del Decreto 2274 de 1986 «que el derecho a decidir acerca de la reproducción pueda ser ejercido libremente por la población» ${ }^{14}$.

En 1987 se creó la Subsecretaría de la Mujer, que institucionalizó el proceso iniciado con la recuperación democrática. Por esos años, también el congreso de la nación ratificó la «Convención para la Eliminación de Todas las Formas de Discriminación contra la Mujer».

Durante el gobierno radical, distintos bloques políticos (del centro y de la derecha laica) presentan varios proyectos de ley solicitando al poder ejecutivo que se implementen consultorios de planificación familiar en los hospitales públicos, que se establezca un régimen de educación en planificación familiar, o, más en general, que se organice el Programa Nacional de Planificación Familiar. Pero al finalizar este gobierno, ninguno de estos proyectos se había puesto en marcha, salvo iniciativas aisladas por parte de algunos centros de salud ${ }^{15}$. A la vez, «se habían convertido en "letra muerta" las normas establecidas, ya que no se había aprobado la normativización que pusiera en funcionamiento la asistencia a través de los servicios de salud» ${ }^{16}$. Haydee Birgin opina que esta situación «podría calificarse de perversa: se consagra un derecho y se obstaculiza su ejercicio» ${ }^{17}$.

En la década siguiente, dentro del contexto discursivo de los derechos humanos, emergen las demandas que visibilizan el cuerpo (anticoncepción,

13. Nos referimos al Decreto 659 de 1974 del gobierno peronista que prohíbe las actividades de control de la natalidad en hospitales públicos y restringe la comercialización de anticonceptivos, y al Decreto 3938 de 1977 de la Junta Militar que prohíbe las actividades de control de la natalidad.

14. Torrado, Susana. Procreación en la Argentina. Hechos e ideas. Buenos Aires: Editorial de la Flor; 1993, p. 278.

15. En la ciudad de Buenos Aires se creó en 1988 el Programa de Procreación Responsable cuyo objetivo fue suministrar información, asistencia y provisión gratuita de anticonceptivos. Funcionó en algunos hospitales durante unos pocos años después de su promulgación.

16. Torrado, n. 14, p. 279.

17. Citado en Torrado, n. 14, p. 279. 
sexualidad, aborto) formuladas en términos de derechos. En el gobierno de Carlos Menem ${ }^{18}$, se constituye el Consejo Nacional de la Mujer que se propuso integrar, en sus propuestas y acciones, una perspectiva de género:

«Una serie de señales hacen pensar que en los años 90 y 91 el flujo de la ola alentada por la apertura democrática llega a un punto de activación importante, y las voces del feminismo y el movimiento de mujeres logran colocar la discriminación de género en el escenario del debate público. Era un momento de ascenso, coincidente con el profundo malestar de las mujeres de los partidos políticos por la escasa representación parlamentaria» ${ }^{19}$.

Sin duda, uno de los logros más significativos fue la movilización de las mujeres de los partidos políticos para lograr la sanción de la Ley de Cupos, coordinada por el Consejo Nacional de la Mujer y el movimiento de mujeres ${ }^{20}$. Pero junto con esta política progresista, el gobierno mantuvo otros espacios en los que dejaba a salvo una posición conservadora, acorde con la injerencia de la iglesia católica ${ }^{21}$. El Gabinete de Mujeres, creado en 1993, expresaba las diferentes tendencias y las contradicciones existentes.

El año 1994 es particularmente importante para el tema que estamos abordando. Por una parte, porque se desarrolla la Conferencia Internacional sobre Población y Desarrollo de El Cairo, en la que se entronizó el concepto de salud sexual y reproductiva. Por la otra, por el desarrollo en Argentina de la reforma constitucional. Así, en el marco de la Convención Constituyente y haciendo gala de su alineamiento con el Vaticano, el presidente Carlos Menem intenta incluir en el texto constitucional una cláusula

18. Carlos Menem gobernó dos períodos: de 1989 a 1995 y luego de la reforma constitucional se acortó el período a 4 años, de 1995 a 1999.

19. Sanchís, Norma. El género en el debate político. Algunas reflexiones sobre actoras, espacios institucionales y políticas públicas entre 1990-1995. In: ADEUEM. Asociación de Especialistas Universitarias de Estudios de la Mujer. Relaciones de Género y Exclusión en la Argentina de los 90. ¿El orden del desorden y el desorden del orden? Buenos Aires: Espacio Editorial; 1998, p. 83.

20. Ley 24012 sobre modificación del Código Electoral Nacional, aprobada a fines de 1991. A partir del 10 de diciembre de 1993, hubo 25 nuevas diputadas, casi un 20\% de los 127 legisladores elegidos.

21. Si bien la posición de la iglesia católica sobre los derechos sexuales y reproductivos se tornó un «estandarte de identidad institucional» y está absolutamente ligada al peronismo, no nos ocupamos especialmente de esa relación en este trabajo. Pecheny, Mario. Yo no soy progre, soy peronista: ¿Por qué es tan difícil discutir políticamente sobre el aborto? Lima, UPCH, 2005. Disponible en: http/ www.ciudadaniasexual.org [citada 27 Oct 2010]. 
referida a «la protección de la vida desde la concepción y hasta la muerte natural». Frente a esta situación, los actores políticos tuvieron que tomar posiciones explícitas. Feministas e integrantes del movimiento de mujeres tenían, por estos años, en suspenso el tema del aborto, pues su contenido subversivo impedía el avance en otros planos políticos. El aborto, sobre el que nadie quería hablar, sobre el que autoridades, legisladores y legisladoras respondían con evasivas, se ubicó en el escenario central. Los partidos políticos abandonaron la estrategia del mandato partidario para dejar a sus integrantes librados a su propia conciencia. Quedó así en evidencia, que las cuestiones referidas al cuerpo de las mujeres, a la procreación, a su derecho a la autonomía, no podían trascender el ámbito de lo personal y constituían - en términos de Rancière ${ }^{22}$ - un núcleo de desacuerdo.

La amenaza de la «cláusula Barra» ${ }^{23}$ tuvo un saldo absolutamente positivo para el activismo mujeril. El colectivo «Mujeres Autoconvocadas para Decidir en Libertad (MADEL)» lideró la resistencia, a través de la cual se logró hacer confluir a políticas, feministas y mujeres participantes de la Convención Constituyente, en la propuesta contraria a la gubernamental.

La presencia de la iglesia católica fue constante a través de su jerarquía y de sus voceros más reconocidos. Las argumentaciones de la coalición del movimiento de mujeres y feministas se centraron en las condiciones socioeconómicas de las mujeres pobres que mueren por aborto, desnudando la ausencia de políticas y generando debates en torno a la educación sexual, la baja calidad de los servicios de salud y la incompatibilidad de estas prácticas con el ejercicio democrático.

Las alianzas y posiciones tomadas por el radicalismo y otros partidos, contrarias al artículo anti-aborto propuesto por Menem, podían hacer peligrar otro acuerdo - a través del famoso Pacto de Olivos- alcanzado previamente entre el presidente y el líder del principal partido opositor, Alfonsín, referido a la posibilidad de reelección presidencial. La cuestión se resuelve al acordar una redacción en la que se menciona el compromiso estatal sobre un régimen especial de protección del niño en situación de desamparo desde el embarazo hasta la finalización de la educación elemental, y de la madre desde el embarazo hasta la culminación de la lactancia.

\footnotetext{
22. Ver cita n. 7.

23. Rodolfo Barra, abogado católico, ministro de Justicia del gobierno de Carlos Menem, fue quien llevó adelante en la convención constituyente la propuesta mencionada.
} 
La orientación conservadora del gobierno menemista quedó en evidencia en el alineamiento de la delegación argentina con los sectores fundamentalistas durante la Conferencia de Beijing, en la renuncia de todo el equipo del área de educación debido a las presiones de la iglesia, contraria a la inclusión de los conceptos de género, tipos de familia y evolución ${ }^{24}$ dentro de los nuevos contenidos educativos y en el establecimiento del 25 de marzo como conmemoración anual del «Día del niño por nacer» ${ }^{25}$. La doctrina de la iglesia católica, constituida en integrista y asumida por el estado, encontró en éste un garante de sus preceptos ${ }^{26}$.

Si tomamos en cuenta, además, que la plataforma partidaria del Justicialismo expresaba que la «Propuesta política para la mujer argentina»se orientaría a desarrollar una «fuerte política natalista a través de la promoción estatal» ${ }^{27}$, queda claro que la perspectiva de género sostenida, excluía cualquier tipo de medida o acción que pretendiese cambiar el supuesto destino maternal de las mujeres.

\section{La cuestión de la mujer en La Pampa. Contexto de surgimiento de la Ley de Procreación Responsable}

De signo justicialista desde la recuperación democrática, la provincia de La Pampa, siguiendo lineamientos políticos nacionales, crea en 1992 el Consejo Provincial de la Mujer y unos años más tarde, el Servicio de Violencia Familiar, ambos dependientes del Ministerio de Bienestar Social ${ }^{28}$. En su

24. La inclusión de estos conceptos dentro de los CBC (Contenidos Básicos Comunes) que se pretendió introducir en la reforma educativa, dio como resultado la renuncia de todo el equipo técnico del PRIOM (Programa de Igualdad de Oportunidades para la Mujer en el Área Educativa), encabezado por Gloria Bonder, durante la gestión del ministro de educación Jorge Rodríguez, en julio de 1995.

25. Instituido por el Decreto 1406 de 1998.

26. Al respecto, consultar: Di Liscia, María Herminia. El derecho a decidir. El camino de Procreación Responsable al debate actual sobre la ley de aborto. Ponencia presentada en $V$ Congreso Latinoamericano de Ciencia Política, organizado por la Asociación Latinoamericana de Ciencia Política (ALACIP). Buenos Aires, 28 a 30 de julio de 2010 [inédita]; Di Liscia, María Herminia. Mujeres en los movimientos sociales en Argentina. Un balance del último siglo. Cadernos de Estudos Latinoamericanos. 2010; 6: 141-180, y Brown, Josefina. Derechos, ciudadanía y mujeres en Argentina. Política y Cultura. 2004; 21: 111-125.

27. Torrado, n. 14, p. 279.

28. Unos años más tarde, el Consejo Provincial de la Mujer pasó a tener dependencia directa del Gobernador. 
formulación de objetivos, el Consejo Provincial de la Mujer establece que se dirige a:

«revalorizar el rol social de la mujer, para fortalecer desde lo institucional un modelo de mujer que responda a las necesidades de la familia, de la comunidad y fundamentalmente a su condición de tal» ${ }^{29}$.

El término género no había desembarcado aún en el ámbito provincial. La visión sobre «la mujer» que sostiene el mandato fundacional del Consejo, reitera las inscripciones convencionales y tradicionales sobre las mujeres, ratificando su ubicación social como sostén familiar y prestadora de servicios a la comunidad, a través de las funciones asistenciales y reproductivas.

No hemos localizado antecedentes institucionales en la provincia para contextualizar la ley objeto de nuestro análisis, que fue aprobada unos meses antes de la organización del Consejo. La inexistencia previa de programas, reglamentaciones, ordenanzas ministeriales, etc. que mencionaran la anticoncepción, la sexualidad y/o la planificación familiar, nos motivó a recurrir a informantes clave ${ }^{30}$, tal como hemos comentado precedentemente.

Todas recuerdan la constitución de un área de trabajo conjunta entre varias reparticiones de la Subsecretaría de Salud Pública (Educación para la Salud, Sanidad Escolar y Salud Mental) con otras del Ministerio de Educación, que llevó a cabo, durante varios años, talleres sobre educación sexual con docentes y personal sanitario, tanto en la capital como en localidades del interior de la provincia. Esta tarea, desarrollada con grandes resistencias - fundamentalmente por parte de las autoridades educativas-, se interrumpió a principios de la década del noventa. Una de las entrevistadas rememora: «Al principio, era cuando reverdecía la democracia y todo se permitía. Después vinieron las complicaciones, ya en los 90 no teníamos vehículo, no nos podíamos mover al interior, nos ponían trabas para todo, nos controlaban lo que decíamos» ${ }^{31}$. Las acciones fueron mermando hasta

29. Web del Consejo Provincial de la Mujer. Disponible en: http/www.lapampa.gov.ar/CPM [citada 15 May 2010].

30. Si bien la pregunta realizada a todas se refirió a antecedentes sobre la Ley de Procreación Responsable, es interesante tomar en cuenta que todas las entrevistadas asociaron la pregunta con la educación sexual. Al indagar sobre si conocían si en los hospitales se realizara algún tipo de asesoramiento sobre anticoncepción, plantearon que estaba prohibido hacerlo.

31. Erbetta, Nilda. Entrevista personal realizada el 15 de agosto de 2010 en Santa Rosa. La Dra. Erbetta ocupaba el cargo de médica de Sanidad Escolar en esos momentos. 
que directivas expresas del ministro de educación de la nación, Jorge Rodríguez, - que hizo su paso previo por la misma repartición en la provincia de La Pampa- eliminaron todo tipo de actividades y contenidos que refirieran a educación sexual.

Con Silvia Gallego, autora de la ley, mantuvimos extensas entrevistas que nos permitieron conocer los avatares del proceso desde sus inicios hasta la promulgación. En los encuentros, reconstruimos también su vida de militante, su niñez y aprendizaje junto a su madre, una de las primeras legisladoras de la provincia Eva Perón y su inserción en el gobierno peronista ${ }^{32}$.

La anticoncepción y la planificación familiar estaban lejos de constituir temas de debate y consideración partidaria. Sólo un pequeño sector de militantes y a la vez profesionales y trabajadoras de la salud, acompañó el proceso de presentación de la norma. En un contexto en el que aún no existía la Ley de Cupos, que se aprobó unos años después en La Pampa, Silvia Gallego era la única mujer de su bloque parlamentario.

Su primera incursión en el tema de salud de la mujer fue la redacción de una ley, que fue aprobada, sobre obligatoriedad de realización del test de Papanicolau y examen ginecológico para el ingreso a la administración pública $^{33}$. Después, y antes de centrarse en la Ley de Procreación Responsable, reconoce haber seguido con profundo interés los hitos nacionales que supusieron la derogación del Decreto 659/1974 y la creación del primer organismo que visibilizó las cuestiones de las mujeres. Pero fundamentalmente, refiere el impacto personal que en ella tuvo el comparar sus posibilidades, sus derechos, con los de otra mujer que llega a pedirle ayuda:

«Yo fui a trabajar esta ley que tenía que ver con los problemas que se te presentan en la cotidianidad (...) la que más me marcó fue la de una compañera del Barrio Matadero, su esposo era un hachero. (...) Esta compañera tenía 7 hijitos, estaba embarazada (...) y bueno, venía desesperada a decirme - vengo a que por favor me ayude que me hagan algo porque yo no puedo seguir teniendo más hijos, - bueno y ¿cómo te cuidás? ¿qué haces?, - yo no me cuido con nada, ¿cómo voy hacer? - pero, a ver ¿fuiste a un ginecólogo, qué hiciste, no tomás pastillas, tu marido no usa profilácticos? Entonces ella me cuenta la realidad de su familia. Claro, cuando el marido venía acá, que venía cobrado, qué hacía: compraba una botella de vino (tomaba vino que

32. Datos biográficos en n. 9.

33. Ley Provincial 1069. Examen preocupacional/Ingreso a la función pública/Examen ginecológico. In: Boletín Oficial, Legislatura de La Pampa, 8 de agosto de 1988, p. 1234. 
no había tomado durante toda la semana o durante quince días, o 20 días, 30 días) se emborrachaba y después los dos querían hacer el amor. Y si ella supuestamente no quería, él si iba a querer. Y ni hablar de usar el profiláctico porque se negaba y tampoco podía ella decir: a ver cómo está el moco, no, hoy podemos hoy no podemos. No, no funciona así. Y nunca había podido acceder a los anticonceptivos orales si tenía 7 chicos. Bueno, y ¿cómo lo resolvíamos? Hablé con un ginecólogo amigo, pedí que la atendiera y que después que tuviera el bebé viera cuál era el método más efectivo. Y ese compañero me dijo: bueno, es una mujer joven y sana, el método más efectivo es colocar un DIU pero en el hospital no se lo pueden colocar porque está prohibido. ¿Cómo que está prohibido? y, si está prohibido, porque acá se sigue aplicando un decreto de la época de Onganía que se había revertido en los hospitales de la municipalidad de Buenos Aires, pero no en los hospitales de las provincias. Y a partir de ahí me puse a trabajar en el armado de la ley. Me reuní con algunas compañeras, asistentes sociales, psicólogas, obstetras, bueno, todas veníamos con la misma preocupación pero yo quiero reiterarte esto, yo entré a este tema desde esa naturalización que tiene ver con las cosas que la clase media da por (...) como derecho per se, y que en realidad cuando vos te movés en otros ámbitos no existe» ${ }^{34}$.

El contacto con la situación de una mujer - que representa a tantas- no sólo la conmociona notablemente, sino que le permite palpar las desigualdades de género, reflexionar sobre su militancia y resignificar su propia biografía e identidad política.

Gallego recoge la tradición y mística peronista - vivenciada desde pequeña en su hogar y con otras congéneres-, que establece que los varones desarrollan actividad política y las mujeres, además, no deben desprenderse de la acción social que las liga a la comunidad, a los problemas del hogar y a los asuntos del ámbito privado ${ }^{35}$. Con otras compañeras del partido, pudo percibir la generalización de la problemática que se había presentado de manera singular, al realizar reuniones y talleres en varios puntos de la provincia. Así, reúne demandas de las mujeres pobres y al dar cuerpo a la ley hace suyas aquellas frases de Evita: «donde hay una necesidad, hay un derecho» $\mathrm{y}$ «cuando se quiere se puede, y cuando se puede, se debe».

\footnotetext{
34. Gallego, Silvia. Entrevista personal realizada el 9 de enero de 2009 en Santa Rosa.

35. Bianchi, Susana; Sanchís, Norma. El Partido Peronista Femenino. Biblioteca Política Argentina, Tomo 208-209. Buenos Aires: Centro Editor de América Latina; 1988.
} 


\section{Contenido y debate de la Ley de Procreación Responsable}

La ley prevé información, prestaciones de servicios y distribución gratuita de anticonceptivos no abortivos, controles de salud, tratamientos de infertilidad y capacitación al recurso humano que llevará adelante el programa, para que toda la población que lo requiera, tenga asegurado «el derecho humano de decidir libre y responsablemente sobre sus pautas reproductivas» ${ }^{36}$.

Legislatura, partido/gobierno, iglesia y corporación médica fueron los escollos que había que sortear para que la ley pudiera ser aprobada. Con respecto al primero, como presidenta de la Comisión de Legislación Social, al presentar el proyecto dentro de la misma, Gallego obtuvo el apoyo tanto de sus compañeros peronistas, como de la bancada radical. De esta última, además, contó con la argumentación de la otra mujer que había en ese momento en la Cámara, la diputada Ángela Ferreti.

Veamos ahora los fundamentos de las exposiciones.

Gallego elige una modalidad altamente emotiva al revelar trece testimonios con los que busca dar presencia a la complejidad de la problemática abordada, y situarla como vivencias cotidianas mujeriles. Abre una contienda en el campo discursivo a partir de nombrar lo nunca antes nombrado $^{37}$ e interpela a la audiencia en su sensibilidad ética. Pone en palabras las múltiples facetas de la indefensión, la falta de posibilidades de decidir y la imposición del mandato maternal hacia las mujeres pobres ${ }^{38}$. Asume no sólo el papel de representante en su acepción clásica, sino que otorga legitimidad a ciertas posiciones de sujeto, mediante una función nominadora, en el sentido de ejercer autoridad para instalar términos en el discurso legislativo, «actuando así como ancla, referente o garante de que

36. En su artículo 4 la ley menciona: «Los métodos anticonceptivos que los profesionales médicos podrán prescribir son: a) de abstinencia periódica, b) hormonales o química y c) mecánicos y/o de barrera: óvulos, cremas, espermicidas, diafragmas, condones, dispositivos intrauterinos». Además se faculta a la Subsecretaría de Salud Pública a incorporar nuevos métodos no abortivos para ambos sexos, debidamente investigados. Ley Provincial 1363. Programa de Procreación Responsable. In: Diario de Sesiones, n. 8, p. 859-860. Durante esta época no se había difundido ni generalizado el uso del condón como preventivo del HIV/SIDA, lo que redunda en la utilización casi exclusiva de métodos que apliquen las mujeres y su reflejo en la regulación de sus capacidades maternales.

37. Segato, n. 1, p. 8.

38. En los testimonios se menciona el embarazo adolescente, la violencia, el abuso, el alcoholismo, el mal uso de las pastillas anticonceptivas, los abortos mal hechos, la pobreza, el deseo de no tener más hijos. 
el discurso es válido y el sufrimiento social que nomina está oficialmente reconocido» ${ }^{39}$.

Interrumpida en varias oportunidades por gritos en el recinto ${ }^{40}$, no ahorra críticas al decreto del gobierno peronista que regulaba la venta de anticonceptivos y rescata la derogación del mismo por el gobierno de Alfonsín. Plantea, además, la planificación familiar a través de tres instrumentos: la declaración de Alma Ata, la Convención para la Eliminación de todas las formas de Discriminación contra la Mujer y la Ley 1343, sancionada poco tiempo antes en la Legislatura pampeana sobre protección de derechos del niño ${ }^{41}$.

En su larga alocución menciona también datos sobre el uso de anticonceptivos en Argentina, la mortalidad materna por abortos, complementándolos con cifras del Hospital Lucio Molas de Santa Rosa ${ }^{42}$. Finalmente cerró su exposición de esta manera:

«quiero resaltar nuevamente que esta Ley está por la vida, no avala el aborto, no es compulsiva, este programa se brindará a quienes así lo requieran, no a la inversa, pero sí promoverá que la comunidad esté suficientemente informada y asesorada para tomar libremente las decisiones. Los métodos que completan este programa en ningún caso serán abortivos (...) esta Ley no apuesta al natalismo ni al antinatalismo, apuesta a que el Estado genere las condiciones para que las parejas puedan decidir libremente la cantidad y el espaciamiento de los hijos que se deseen tener. Tanto es así que se enuncia expresamente que la Subsecretaría de Salud Pública, deberá facilitar la información y la accesibilidad a los recursos necesarios para el tratamiento de la infertilidad» ${ }^{43}$.

39. Segato, n. 1, p. 9.

40. El Diario de Sesiones que registra el debate da cuenta de varias interrupciones mientras Silvia Gallego expone. Al tratar de caracterizar cuál era el público, las informantes consultadas explicaron que la colmada presencia en el recinto no era por esta ley, sino por una próxima referida a la reforma educativa, que se creía iba a ser tratada ese día y que tenía numerosos sectores docentes en contra.

41. El art. 8, inciso f) establece que se desarrollará «la atención preventiva, la orientación a los padres y la educación y servicios en materia de planificación familiar». Ley Provincial 1343. Normas de Protección a la Minoridad. In: Boletín Oficial, Legislatura de La Pampa, 8 Nov 1991, p. 1546-1547.

42. "quiero introducir las cifras de nuestro hospital de referencia, que dice que en el hospital de Santa Rosa, de dos a cinco mujeres, en su gran mayoría jóvenes, con abortos provocados en forma ilegal, obliga a realizar legrados para preservar su salud». Diario de Sesiones, n. 8, p. 839. No se han localizado otros datos sobre salud reproductiva en el período.

43. Diario de Sesiones, n. 8, p. 840. 
Ángela Ferreti se refiere en primer término a la familia como el grupo primario más importante de la sociedad, pero inmediatamente señala que el hombre no es el único jefe de la misma, en función del papel que la mujer ha ido desempeñando en los últimos tiempos, papel que se ha reconocido en la legislación. Menciona entonces la «libertad sexual» que la mujer no sólo ha reclamado sino que en la realidad practica. A continuación, advierte sobre el agobio económico que puede derrumbar la armonía conyugal, la existencia de hijos no deseados que pueden sufrir carencias afectivas y materiales, y la llegada a las situaciones de aborto como control de la natalidad. Finalmente expresó su apoyo señalando:

«Porque creemos que con esta Ley estamos contribuyendo a aportar solución, sobre todo a las mujeres y a las familias de escasos recursos (...) porque estamos a favor de un proyecto de vida en contra de todo lo que signifique destrucción de la vida, el bloque de la Unión Cívica Radical adelanta, por mi intermedio, el voto favorable al presente proyecto de ley» ${ }^{44}$.

La ley fue apoyada por 18 legisladores y legisladoras ${ }^{45}$. En el debate, hubo una única intervención que se manifestó en contra.

El diputado Héctor de la Iglesia, justicialista ${ }^{46}$ de reconocida militancia católica, hizo una encendida presentación contraria al proyecto, pero no arrastró a otros compañeros de bloque. Expuso sobre cuestiones poblacionales - la explosión demográfica mundial, en contradicción con la situación de Argentina, y específicamente de La Pampa «donde la densidad no pasa de dos habitantes por kilómetro cuadrado» ${ }^{47}-$, conjuntamente a la importancia geopolítica, para centrar su crítica en que una «procreación responsable» como establece la ley, en realidad tiende a «evitar la concepción de vida humana por instrumentos naturales y artificiales» ${ }^{48}$ e impide el control del instinto por la razón y la voluntad. También se explayó sobre los efectos negativos de las píldoras anticonceptivas y en las características

\footnotetext{
44. Diario de Sesiones, n. 8, p. 842.

45. Antes de la reforma de la Constitución de la provincia de La Pampa, la Legislatura contaba con 21 legisladores/as. En la sesión en que fue aprobada la Ley 1363, había un diputado ausente, hubo dos abstenciones, una del diputado Héctor de la Iglesia, la otra no se encuentra identificada en el Diario de Sesiones.

46. El peronismo también se denomina justicialismo, por cuanto define como valor político central defender la justicia social.

47. Diario de Sesiones, n. 8, p. 862.

48. Diario de Sesiones, n. 8, p. 862.
} 
abortivas del DIU. Otra de las críticas fue que la ley omitía un programa de educación sexual en las escuelas, tanto primarias como secundarias y en sus tramos finales se refirió a la moral cristiana, según su criterio, correctamente aplicada por la Corte Suprema de Justicia de la Nación en oportunidad de rechazar la solicitud de personalidad jurídica de la Comunidad Homosexual Argentina (CHA) ${ }^{49}$, al indicar «que la sexualidad tiene como objetivo ínsito la reproducción de la especie». Como broche final, destacó su pertenencia al partido:

«Para los justicialistas - y es por ello que lo soy- hay por fin otro argumento: la verdad número catorce dice que el peronismo es una doctrina profundamente humanista y cristiana, este fundamento de tipo moral no puede ser desconocido por ningún justicialista...» ${ }^{50}$.

Las legisladoras hacen audible en el recinto un discurso de libre decisión, con referencias a la sexualidad y a la anticoncepción; nombran y dan voz a las necesidades de las mujeres. El legislador Héctor de la Iglesia, sin embargo, nunca incorpora en su discurso al término «mujeres». Por el contrario, su alocución está plagada de términos como «reproducción», «instintos naturales», «control de la natalidad», «recursos poblacionales».

\section{Del debate a la promulgación}

La estrategia de Silvia Gallego con su partido, fue comunicar el proyecto cuando ya estaba listo para ser presentado, con el objeto de impedir debates, enfrentamientos y evitar lo más posible las presiones. Pero el proyecto fue aprobado en la última sesión de esa legislatura, y luego debía cumplir el camino burocrático previsto para ser efectivamente ley ${ }^{51}$. Para evitar un

49. En diciembre de 1989 la Secretaría de Justicia deniega la personalidad jurídica de la CHA. En noviembre de 1991 la Corte Suprema declara improcedente el recurso extraordinario y la queja presentada por la CHA. Se realiza una campaña internacional de apoyo y, frente a estas presiones, se otorga por decreto la personería jurídica en marzo de 1992. Web de la Comunidad Homosexual Argentina. Disponible en: http://www.cha.org.ar.CHA [citada 2 Nov 2011].

50. Diario de Sesiones, n. 8, p. 862.

51. Esta situación, aunque con resultado inverso, se repitió en la aprobación de la Ley de Protocolización de Abortos No Punibles, vetada por el gobernador entrante a fines de 2007. 
posible veto ${ }^{52}$, que el círculo cercano al gobernador había anunciado, y en complicidad con funcionarios de la legislatura, la ley no fue enviada al poder ejecutivo, sino que llega una vez que ha asumido el nuevo gobernador.

«Pero después había que promulgarla con el nuevo gobierno, y ahí vino un nuevo embate muy duro al gobierno de Marín. Te diría que la parva de telegramas que vinieron, que llegaron al gobierno fue impresionante (...) a través de redes informales que ha tenido desde siempre la iglesia. [...] La estructura de la iglesia nunca tuvo problemas de funcionamiento. [...]mirá, me acuerdo, hasta los obispos de Chile mandaron, y de todas las provincias, donde hay centros de Acción Católica, los Boy Scouts, el mundo (...) Yo tengo que reconocer en esto que el proceso de la promulgación en la etapa de Marín, fue un proceso de un debate interno ideológico muy importante en el gabinete (...) así que esta es la historia de cómo sale y cómo no fue vetada» ${ }^{53}$.

Sigilo, táctica sorpresa, o la que más adelante - al referirse a la aprobación de la ley que prevé la ligadura de trompas- denominarán metodología «sottovoce», fue la maniobra elegida en el convencimiento de que realizar un debate, iba a malograr su sanción. En la discusión interna, debió esclarecerse que la nueva ley nada tenía que ver con el aborto, y también que, aunque se preveía el DIU, este no era abortivo. Hubo intentos - dentro del grupo político cercano al gobernador- para que éste vetara el artículo referido a medios medicalizados de anticoncepción, dejando sólo los naturales, pero no prosperó, ya que desvirtuaba totalmente la ley.

Al iniciarse el siguiente gobierno, Gallego es nombrada ministra de Bienestar Social (cartera a la que le competía la implementación de la ley, puesto que incluye la Subsecretaría de Salud Pública) y tres de los diputados que habían votado favorablemente ocuparon otros tantos ministerios.

La iglesia local rápidamente comunicó la alerta a diferentes provincias, obispados y parroquias, y el gobernador recibió llamadas telefónicas y telegramas de todos los puntos del país, incluso de países vecinos. No faltaron las alusiones personales contra la autora de la ley, que fue nombrada como promotora de la destrucción familiar en los sermones de la misa navideña. Las presiones eclesiásticas llevaron al gobierno a la disyuntiva de aceptarlas,

52. Debemos señalar que el gobernador saliente era Néstor Ahuad, perteneciente a una línea interna del Partido Justicialista diferente a la de Silvia Gallego. El nuevo gobernador electo era Rubén Marín, de la misma línea interna que ella.

53. Gallego, n. 34. 
y ser permeables a su influencia; o actuar autónomamente, haciendo valer su autoridad; cuestión que finalmente ocurrió, ya que la ley fue promulgada, aunque no a través de un instrumento a tal efecto, sino por los plazos administrativos previstos para cualquier norma.

La visita a hospitales y el contacto con médicos, para conocer de qué manera se presentaban demandas en los establecimientos públicos, dio como resultado un enfrentamiento con ese sector, puesto que al contemplar la ley la colocación de DIU, se afectaba un nicho económico muy preciado por la corporación:

«va a v aparecer un problema con este sector, porque atacamos un nicho que es muy redituable, que no está nomenclado (las obras sociales trabajaban con nomenclador en esa época), que no lo cubren las obras sociales y el hospital tampoco, y que entonces empezamos a averiguar cómo estaba la situación. Y ahí descubro que existía algún sistema muy perverso de círculo cerrado para colocarse el DIU (...) donde los ginecólogos reunían, supónete, si cobraba trescientos pesos la colocación del DIU, reunían cinco mujeres que pagaban cincuenta pesos por mes cada una y les iba colocando uno por mes (...) Un círculo cerrado de ahorro previo, si señora, como el televisor! (...) Ahora, si quedabas embarazada: ¡perdiste! ¡siga participando!» 54 .

\section{La procreación responsable y la matriz del peronismo: un significado posible}

Como hemos visto, la ley 1363 surge sin antecedentes previos tanto en el contexto nacional como provincial. Más allá de las motivaciones personales - ya expuestas - de la autora y la coyuntura política que hizo posible su aprobación, nos interesa explorar los términos y significados presentes en la nueva norma.

Susana Checa al reseñar las políticas de control de la natalidad en América Latina en la década del 60 con relación a la explosión demográfica y a las ideas desarrollistas, explica que el concepto rector de esos programas era el de «planificación familiar» ${ }^{55}$. Dentro de éste, los anticonceptivos tenían

\footnotetext{
54. Gallego, n. 34.

55. Checa, Susana. Control de la natalidad. In: Gamba, Susana, coord. Diccionario de estudios de género y feminismos. Buenos Aires: Editorial Biblos; 2007, p. 67-70.
} 
por objetivo delinear una familia ideal, pensada racionalmente, célula del desarrollo económico y social de los países, como así también prevenir el aborto y disminuir la mortalidad materna originada en esa causa ${ }^{56}$. Con matices, estos argumentos fueron sostenidos en las Conferencias de Población de las Naciones Unidas anteriores a la de El Cairo (1994) ${ }^{57}$.

Desde mediados de los 80 , la fuerte incidencia del movimiento de mujeres produce un cambio de paradigma al poner el eje en la salud sexual y reproductiva, y la incluye dentro de los derechos humanos. Definida como un estado de bienestar físico, social y mental vinculado al sistema reproductivo, el concepto:

«enfatiza sobre el ejercicio de la sexualidad de manera autónoma y responsable, libre de riesgos y de coerción o violencia, y desligada de la procreación. Así como también la decisión libre, autónoma e informada de las parejas para decidir el número de hijos que desean tener y acceder a la información sobre su vida sexual y reproductiva ${ }^{58}$.

Podemos conjeturar que la expresión «procreación responsable» surgió como concepto bisagra u opción intermedia entre el de «planificación familiar» y el de «salud reproductiva» ${ }^{59}$, éste último aún no generalizado en los discursos de principios de los 90, por lo menos en los círculos políticos ajenos al feminismo. Con el mismo, no se obvia la anticoncepción, pero se remite a un término positivo: $\operatorname{procrear}^{60}$. Si bien la ley hace alusión a

56. Felitti, Karina. Derechos reproductivos y políticas demográficas en América Latina. Iconos. 2009; 35: 55-66.

57. Nos referimos a las de Bucarest (1974) y México (1984). ONU. Resultados sobre la población Disponible en: http/www.un.org/es/development/devagenda/population.shtml [citada 15 Nov 2011].

58. Checa, n. 55, p. 69.

59. Gloria Luoni, colaboradora de Silvia Gallego recordó: «lo elegimos como superador de la planificación familiar, porque comprende la posibilidad de decisión de las mujeres. Planificación familiar nos sonaba a McNamara».

60. Los debates sobre la terminología aún continúan en el presente. En CONDERS (Consorcio Nacional de Derechos Reproductivos y Sexuales). Monitoreo Social Provincia de La Pampa. Informe Final. Santa Rosa: 2008 [documento inédito], se señala que la responsable de Maternidad e Infancia expresó: «no hay una división entre mujeres que no quieren tener hijos y mujeres que quieren tener hijos, en el control prenatal ya tiene que estar internalizado el concepto de anticoncepción». Pero aclaró que esa palabra no le gustaba y prefería procreación responsable, recalcando que para que un bebé sea deseado y un embarazo bien controlado, se requiere de intervalos intergenésicos. Además agregó que cuando desde Salud Pública se presentan con el Programa de Procreación Responsable suelen ser acusados de intentar 
la salud reproductiva, podemos entender que la nominación de lo nuevo que se desea consagrar requirió de una elección estratégica, al incorporar sobre todo la preocupación social hacia las más pobres, aspecto central del discurso peronista ${ }^{61}$.

Recordemos que la inclusión política de las mujeres durante el peronismo se inscribió en la doctrina del maternalismo ciudadano, que condiciona y remite los derechos a la función reproductora, pues el aumento poblacional contribuiría a la soberanía de la patria y de la nación. La identidad femenina aunó la participación política con el compromiso comunitario y social, cuya figura central es la madre y el hogar, en la que la impronta de la tradición católica es evidente. En la consideración de los derechos de las mujeres por parte del pensamiento común maternalista ${ }^{62}$, salen a la luz las antiguas alianzas entre el peronismo y la iglesia que tuvieron los primeros gobiernos ${ }^{63}$.

En la formulación de esta ley, podemos advertir una ruptura de este arquetipo y la silueta de un cuerpo de mujer con derechos y decisiones para ser contada ${ }^{64}$ en el reparto democrático. Sin estridencias, abriéndose paso con trabajos de base previos, transitando un camino sinuoso se pudo llegar a una ley posible, impensada inclusive para años posteriores. En los 90, la iglesia local no había activado a sus fieles y no tenía voceros autorizados, cuestión que se revertirá a posteriori y que puede notarse en el tratamiento de otras normas.

controlar la natalidad, aclarando que no está a favor de que la mujer no procree o procree como el Estado quiera, sino que ejerza su derecho a decidir.

61. Tomemos en cuenta también que «procreación responsable» se mantiene en las leyes que se sancionaron más tarde, junto a «salud sexual y reproductiva», como en la Ley Nacional 25673 de Salud Sexual y Procreación Responsable de 2002 y la Ley 418 de 2000 de Salud Reproductiva y Procreación Responsable de la Ciudad Autónoma de Buenos Aires.

62. Di Liscia, María Herminia. «Ser madre es un deber». Maternidad en los gobiernos peronistas, 1946-1955. In: Villar, Daniel; Di Liscia, María Herminia B.; Caviglia, María Jorgelina, eds. Historia y género. Estudios sobre la condición femenina. Buenos Aires: Editorial Biblos; 1999, p. 33-51.

63. Juan D. Perón fue presidente entre 1946-1952 y entre 1952-1955 en que fue interrumpido su gobierno por un golpe militar. Fue elegido para un tercer período entre 1973-1977, que no pudo completar puesto que falleció el 1 de julio de 1974.

64. Rancière, n. 6. 


\section{Conclusiones y proyecciones al presente}

Si bien no se ha realizado una evaluación estadística del desenvolvimiento del Programa de Procreación Responsable, diferentes fuentes (promotores o efectores de salud, contacto con usuarias, informaciones procedentes del interior de la provincia y otros informes o relevamientos) ${ }^{65}$ nos permiten afirmar que, con vicisitudes internas y externas, la ley ha estado sujeta a una implementación fragmentaria e intermitente.

La iglesia perdió la batalla en 1991 al aprobarse la ley, puesto que su presión tanto local como nacional, no impidió que se promulgara. Pero ganó otra: el silencio, la recortada difusión, la no reglamentación, una tímida implementación en la capital en los primeros años de vigencia y el ocultamiento en casi todo el interior de la provincia ${ }^{66}$, lo que muestra que nunca abandona la injerencia en sus temas de interés ${ }^{67}$.

Esta presión no necesariamente se manifiesta de manera directa, sino que se filtra a través de la identidad religiosa de jueces y juezas, legisladores y legisladoras y personal funcionario en general. Aunado a esto, señalemos la convivencia ideológica dispar tanto del peronismo como del radicalismo $^{68}$ y que dentro del proceso analizado puede advertirse en el nulo papel desempeñado por el Consejo Provincial de la Mujer, organismo al que le competiría un papel protagonista, por lo menos, en la difusión de la ley.

La provincia de La Pampa fue pionera en la aprobación de la ley que hemos analizado, ya que, tal como plantean Mario Pecheny y Mónica Petracci, las leyes nacionales referidas a salud reproductiva en Argentina, solo se sancionan veinte años después del retorno a la democracia ${ }^{69}$.

65. Nos referimos al Informe del CONDERS, n. 60, y al contacto con profesionales de la salud pertenecientes o allegados a la agrupación «Mujeres por la Solidaridad».

66. El Consejo Provincial de la Mujer nunca realizó una difusión de la ley. Esto pudimos advertirlo al realizar una capacitación con mujeres del interior. Al ponerlas en conocimiento de la ley y dirigirse a los hospitales de sus pueblos, también se encontraban con la ignorancia de todo el personal de los mismos.

67. Di Liscia, María Herminia. Vigencia ininterrumpida de la lucha por los derechos sexuales y reproductivos. In: Di Marco, Graciela; Tabush, Constanza, comps. Feminismos, democratización y democracia radical. Buenos Aires, UNSAM EDITA; 2011, p. 161-176.

68. Abal Medina, Juan (h). Los partidos políticos ¿un mal necesario? Buenos Aires: Claves para todos; 2004.

69. Pecheny, Mario; Petracci, Mónica. Derechos humanos y sexualidad en la Argentina. Horizontes Antropológicos, 2006; 12: 24-48. 
El inicio exitoso de un sector del justicialismo en hacer visibles los derechos de las mujeres no continuó, sino que será la agrupación «Mujeres por la Solidaridad» la que tomará ese lugar. La contradicción entre la ambivalencia de aprobar una norma progresista, y aplicarla restringidamente, permite conjeturar las razones del surgimiento de nuevas identidades que se posicionaron en la defensa de los derechos sexuales y reproductivos y que lideraron los procesos para lograr, posteriormente, la ligadura de trompas y la protocolización de los abortos no punibles.

Para finalizar, si retomamos lo planteado al comienzo del artículo sobre la lucha doble que se desenvuelve en el campo discursivo jurídico ${ }^{70}$, podemos concluir que el Programa de Procreación Responsable efectuó en sus inicios la nominación, pero la cotidianeidad de su apropiación sigue un proceso de construcción aún no finalizado. De hecho, los debates sobre las otras dos normas mencionadas tuvieron un saldo favorable para las mujeres, puesto que promovieron paralelamente acciones de seguimiento y de exigibilidad del Programa de Procreación Responsable, que llevan a cabo «Mujeres por la Solidaridad».

Las exposiciones y colisiones que produce cualquier norma referida a la autonomía de las mujeres, activan las reacciones del patriarcado cuyos niveles de tolerancia ${ }^{71}$ ponen en jaque las identidades políticas y profesionales y permiten, de modo discontinuo y de acuerdo a las diferentes coyunturas, que las «no contadas» emerjan o que, por el contrario, sean ignoradas.

70. Segato, n. 1.

71. Calvera, Leonor. Mujeres y feminismo en la Argentina. Buenos Aires: GEL, 1990. 


\section{An analysis of the first law on contraception in Argentina. The Responsible Procreation Programme in the province of La Pampa}

María Herminia Di Liscia .......................................

1.- Introduction. 2.- The recovery of democracy and women's demands. 3.-The woman's issue in La Pampa. Context of the emergence of the Responsible Procreation Law. 4.-Content and debate of the Responsible Procreation Law. 5.-From debate to proclamation. 6.-Responsible procreation and Peronism: a possible significance. 7.-Conclusions and projections to the present.

ABSTRACT: The passage of a Law requires previous negotiation processes that consider the background, arguments, support and the appropriate terminology for approaching the issue. The legal domain is a discursive field in which a dual struggle develops: to establish designations and to introduce that which the law establishes into everyday practice. Hence, conflictive processes are unleashed in which social agents are confronted by political parties, by institutions and by their own political and subjective identities. This article analyses the development of the "1363 Law», which was passed in November 1991 in the legislature of La Pampa province (Argentina). This Law created a provincial programme for responsible procreation, the first provincial legislation on contraception to be established. Although reproduction also involves males, special account is taken of speeches referring to females, given that the culture superimposes maternity on the female identity and references are therefore weighted towards the condition of women. We use the particularity of this case and its analytical potential in order to understand others, using as empirical material the parliamentary debate and interviews with the author of the Law and with key informants. We address the following questions: What was the national and provincial context in which the Law on responsible procreation was framed? What were the strategies adopted to achieve it? How was contraception articulated within the Peronist worldview of women? What meanings did the term «responsible procreation» bring into play? Finally, we present a brief assessment of the law's application. 